5.

\title{
A Review of Social Features in Social Network Games
}

Janne Paavilainen, Kati Alha, \& Hannu Korhonen

Transactions of the Digital Games Research Association

2017, Vol. 3, No. 2, pp. 113-142

ISSN 2328-9422

http://todigra.org

TEXT: Licensed under Creative Commons Attribution (CC BY-

NC- ND 2.5) http://creativecommons.org/licenses/by-nc- nd/2.5/

IMAGES: All images appearing in this work are property of the respective copyright owners, and are not released into the Creative

Commons. The respective owners reserve all rights.

\section{ABSTRACT}

Although social network games on Facebook have become popular, their actual sociability has been questioned. In this paper, we review the social features of 16 social games and, as a result, present a list of 30 social features in three categories: presence, communication, and interaction. A common set of features, which was found in all of the examined games, is mainly focused on the presence and communication aspects, while 
neglecting player interaction. In addition, social features are primarily used for acquisition and retention purposes, rather than monetization. These findings are useful for the study and design of social features in social games and in other games with social network integration.

Keywords

Facebook, game feature, review, sociability, social games, social networks, video games

\section{INTRODUCTION}

Social network games have become a popular pastime for Facebook users and are played by millions on a daily basis (Fields \& Cotton, 2012). Based on the free-to-play revenue model and social network integration, these games can be acquired free of charge through the network where the games utilize a viral effect of the player's social network for playful purposes (Paavilainen et al., 2013). The player's social network also provides affordances for sociability, which has been acknowledged to have an important role in both games and play (Salen \& Zimmerman, 2004). Researchers have identified the social component to be an important motivator for playing online games (e.g. Yee, 2006; Siitonen, 2007; Kallio et al., 2011).

Social games have caused controversy due to claims of not being "truly social” or being limited in their sociability (Consalvo, 2011; Paavilainen et al., 2013). Their status as games has even been questioned by game industry professionals (e.g. Brightman, 2012; Nutt, 2012). The term "social games" has been considered a misnomer due to the fact that all games are inherently social (Isbister, 2010, Stenros et al., 2011b). This industry-coined term is said to emphasize the social network platform rather than the games being particularly social. As the sociability of 
social games has been questioned, it provides an interesting premise for a closer study.

In this paper, we review the social features of 16 social games. First, we present different views on the sociability of social games as discussed by the academia, the industry, and the players. Then we examine 16 social games and use an applied thematic analysis (Guest et al., 2012) to identify the social features in them. As sociability is one key motivator for playing online games, understanding the actual social features becomes important. Our comprehensive list of 30 social features provides practical examples for practitioners to use in their work.

The nature of our study is a qualitative explorative research, rooting itself in the field of game studies (Mäyrä, 2008). We focus on Facebook social games, as Facebook has become the most popular social network service in the western world and a majority of the discussion and research focuses on social games distributed and played there.

\section{PERSPECTIVES ON SOCIABILITY IN SOCIAL GAMES}

This section explores three perspectives on the sociability of social games: the academia, the industry and the players. The purpose of this section is to gain an understanding of how the sociability of social games has been perceived and discussed by the different stakeholders.

\section{Academic Approach}

The emphasis on single-player games during the digital game era has been an anomaly of sorts in the history of gaming, as games have already been social experiences for centuries (Salen \& Zimmerman, 2004). Sociability is a natural part of games that feature two or more participants, and even single-player games have been argued to be social (Isbister, 2010; Stenros et al., 2011b; Christou et al., 2013). 


\section{ToDiGRA}

According to Salen and Zimmerman (2004), "social” refers to player interaction, which happens on an internal and external level. The internal level emerges from the game's rules, as in the social roles of the characters, while the external level derives from the pre-existing social relationships of the players, which can affect the game. Both levels of social relationships may be modified during the game, and is a way to achieve meaningful play. In social games, a game provides the internal level while the social network provides the external level through friend connections that are potential co-players.

O’Connor et al. (2015) have studied the applicability of three theoretical constructs of social relationships between massively multiplayer online (MMO) game players: psychological sense of community, social identity, and social support. The results indicate that these constructs are present in MMO games and they could determine the optimal game features to enhance positive connections with fellow players. It is possible that these constructs are applicable to social games, as well.

De Kort et al. (2008) have defined that the sociality of the play setting is dependent on the game's social affordances and the players' ability to monitor the other players' actions and behavior by observing, acting, competing, co-operating, or co-acting, while creating opportunities for communication either verbally or non-verbally. Furthermore, Stenros et al. (2011b) have defined a framework for describing social interaction in social games. Sociability can be explored through the layers of presence, communication, and interaction. Each of these layers influences how the players perceive the sociability of a game.

Social presence can increase the players' commitment to the online community, as the players are aware of other players (Friedl, 2003; Ducheneaut, 2006). Presence features can focus on individuals when we want to create a bond-based commitment or it can focus on teams, which would create an identity-based commitment (Farzan et al., 2010). Social presence has been a critical factor for the acceptance of a service 
and promoting continuous usage (Shin \& Shin, 2011). Presence is a prerequisite for sociability in any online game.

Communication between individuals is an essential part of sociability. In traditional multiplayer games, this usually means talking among players in the same space or through an in-game communication channel (Siitonen, 2006; Stenros et al., 2011b). Communication does not always have to be verbal, as noted by McEwan et al. (2012) who studied social interaction on a game site and noticed that there was very little verbal communication among players. Instead, game-based activities were considered a sufficient method of social interaction. Communication is the next step from social presence.

Multiplayer games are often considered to be more interesting and challenging than single-player games due to the player-to-player interaction (Friedl, 2003; Korhonen \& Koivisto, 2007). Fullerton (2008) has categorized different player interaction patterns which enable interaction between the players: single-player vs. the game, player vs. player, multilateral competition, team competition, multiple individual players vs. the game, unilateral competition, and cooperative play. In the multiple individual players versus the game structure, numerous players are playing the game in the company of others, but actions are directed towards the game system and interaction between the players is limited. Multilateral competition means that there are three or more players and they can be either competing or collaborating through the game interaction affordances. Interaction is the third layer of sociability, extending from presence and communication.

Consalvo (2011) has studied multiple social games on Facebook, and according to her study, the most common social mechanics were a friend bar, gifting, visiting, competition/challenge, and communication. Consalvo concluded that social mechanics are quite limited in how they allow players to be social. Simple clicking of icons and the passive presence of friends in the friend bar or a one-line message may not allow the players to engage in deeper social interaction. 


\section{ToDiGRA}

Gifting is a common reciprocal action in social games. Players send and receive gameplay items from each other. Reciprocity strengthens the social ties between the players, reminds them to come back to the game (retention), and also acts as a viral mechanism for spreading the game in the social network (acquisition). Reciprocity can also be problematic because it will create obligation between the players and ignoring a request can be taken as an impolite act (Losh, 2008; Stenros et al., 2011a; Paavilainen et al., 2013).

A player's social network, such as Facebook friends, can be utilized in many different ways in a game. Non-player characters may be named after the player's friends or the player can assign friends for different roles in the game space (Paavilainen et al., 2013). Social games can also require a number of friends for progressing in the game. At first, the player can play the game alone, but as the game advances the player becomes dependent on the help of others (Tyni et al., 2011). This can be problematic for those players who do not have enough playing friends (Losh, 2008; Paavilainen et al., 2013).

Typically, social games have not included in-game communication channels, but they utilize external channels such as Facebook chat. A common method is to post messages to the feeds of the players or their friends on the Facebook wall. Although messaging is important for acquisition and retention, research has shown that such messages can be considered spamming, which is not desirable sociability (Paavilainen et al., 2013; Paavilainen et al., 2015).

\section{Industry Insights}

Game designers have proposed various models (Järvinen, 2009; Ventrice, 2009) for understanding the design of social games, and sociability has been identified as a key aspect. Typically, sociability is discussed in relation to asynchronous gameplay, reciprocity, collaboration, and competition. Although sociability has been seen as an 
important part of social games, the discussion has often focused on the shallow sociability of these games.

Game designer Greg Costikyan (2011) has stated that social games are unsocial. Costikyan considered many social games to be antisocial, as the main social interaction is to attack other players, or asocial, because the gameplay resembles that of solo-playing in an MMO game where other players are present but mostly irrelevant (see also Ducheneaut, 2006). Costikyan proposes features like teams, diplomacy, negotiated trade, and resource competition to create "actually social” games.

Costikyan's views are also shared by others in the game industry. Indie game designer Jonathan Blow has even called social games evil, as instead of being social they are more about exploiting your friend list (Caldwell, 2011). According to Bogost (2010), friends in a social game are merely resources - not only for the players, but also for the developers for viral marketing purposes. Adding to that, Zynga's former studio manager Matthew Wiggins stated that social games lack meaningful interaction and use social networks for viral marketing and spamming (Dredge, 2013).

The ability to play together in a shared physical space or concurrently has been seen as the fundamental aspect of a truly social game (Brightman, 2012; Radd, 2012). Thus, the lack of “real” sociability has been connected to asynchronous gameplay, which allows the players to play without all parties being present at the same time (Rose, 2011). Asynchronicity has been viewed as less valuable than synchronous interaction (Radd, 2012). However, game designer John Romero comments that asynchronicity can also be beneficial for sociability, as the players do not always have the opportunity to play together simultaneously (Grayson, 2012). For this reason, asynchronicity has earlier been proposed as the basis for casual multiplayer games (Bogost, 2004). 
There is also an evolutionary perspective that better practices are picked up as social games evolve (Brightman, 2012; Nutt, 2012). Thus, the games would become more social (Radoff, 2011). This has been apparent in earlier game releases, which have been touted to be "more social" than their predecessors (EA, 2012; Tyni et al., 2011). In addition, the game industry is not completely unanimous about the lack of sociability in social games. Game designer and researcher Aki Järvinen (2010; 2011) takes the opposite stance by stating that there is sociability in social games - it is just the type that best fits the platform. Burdening players with too many social features would take something away from the accessibility and casual feel of social games.

The game design literature on social games is not very focused on sociability either. The social features are brought up mostly to make players more committed through reciprocity and thus enhance retention, or as a means for viral marketing (Fields \& Cotton, 2012; Luton, 2013). In his Game Developers Conference presentation in 2011, game designer Raph Koster proposed 40 social game mechanics for social games. The presentation started with the introduction: "A lot of people have accused social games of not really being social.” (Koster, 2011)

\section{The Players' Perspective}

Hou (2011) has studied the uses and gratifications of social games. By surveying the players $(\mathrm{N}=93)$ of the Happy Farm social game, Hou reported that the expected gratifications of social game players include both social and game motives. The respondents played the game more frequently, spent more time in it, and got more engaged in the social interaction, which was a better predictor for game play variables than the diversion motive (e.g. relaxation, escape from stress, avoiding responsibilities).

Kim et al. (2013) presented the results of a pilot survey study $(\mathrm{N}=80)$ where the relationship between social games and sociability was studied. Both the sociability and the playability perspectives were critical to the 
users' continuous use of the game and positive word-of-mouth behavior. The sociability factor was constructed from the "Social image" and "Maintaining interpersonal interconnectivity" and the formed "Subjective norm" variable was a better predictor of "Behavioral intention to use" than the attitude-related factor.

Wohn and Lee (2013) identified four social game play motivations in a survey study for Facebook game players $(\mathrm{N}=164)$. Two of these motivations were social: building common ground and reciprocity. They found that most players were not playing for social purposes, but the ones who did, devoted more energy on customizing their avatar, customizing their in-game space, publishing their game status on their Facebook wall, and were more inclined to spend real money than players with no social motivations.

The challenge with the aforementioned quantitative studies is that their sample sizes are relatively low. It also remains unknown how the games played by the survey respondents measure against the games analyzed in this study. For example, Chinese social games typically feature conflict mechanics such as stealing items, which are usually not present in western social games (Chen, 2009). Due to these factors, the generalizability of the results is questionable, but they do indicate that sociability has an important role in social games.

Wohn et al. (2011) concentrated on how social games influence the players' social relationships in an interview study with adult Facebook users $(\mathrm{N}=18)$. The participants perceived three outcomes of their social game use on their social relationships: maintaining, initiating, and enhancing relationships. They discovered that while the benefits inside of a game are typically the initial motivation to add friends, the relationships with these friends got stronger through playing the game.

Price \& Wearn (2012) used participatory observation and interviews “to examine the gamers' view of friendship between players of both asynchronous (viral) and synchronous (social) Facebook social 
networking games”. The study was focused on four Facebook games and included individual interviews $(\mathrm{N}=20)$, a group interview $(\mathrm{N}=6)$, and additional email interviews $(\mathrm{N}=3)$. The interviewees were from the western countries and Russia, and they were all female. The results suggest that social games with a higher interaction level have a better "sticky factor", i.e. retention. The authors suggest that if developers wish to aim for better retention and decrease churn (the percentage of people who quit playing in a given period of time), they should add more social elements to these games.

Paavilainen et al. (2013) present an interview study ( $N=18)$ where Finnish Facebook users discussed how they perceive and play Facebook games. The study reports that the players acknowledge the social features in social games as an essential part of their game play, but the depth of sociability was considered rather low. Sociability can also be a burden, a nuisance, or a limiting factor. Assigning friends to certain roles in one's game space might have been considered funny but was hardly seen as social, as usually the other player would not know about the feat. Although receiving gifts was nice, sending them was seen as a chore. Sociability could also be "a hellish annoyance" due to the massive reciprocal message spam from the game and the players. At the same time, Facebook notifications increase the knowledge of games played by trusted friends, thus eliciting curiosity towards those games. The social presence caters for competition, and a group of friends could make up for a poor game design. The feeling of playing for an audience was present, and social games were considered to be single-player games with a social twist.

\section{Summary}

Academia has mainly studied sociability in video games from a holistic perspective, with a tendency to focus on MMO games. A few researchers have addressed social games directly, as the domain is rather new. Sociability has been recognized as an important part of video games and it can have different roles depending on the game. Sociability in games 
is formed through presence, communication, and interaction between the players.

The game industry has been actively discussing social games and their perceived lack of actual sociability. The tone of discussion has often been negative, even judgmental. Some comments reflect an evolutionary stance as social games are expected to "mature” and become more social in the future. Some designers consider that social games do not need deeper sociability as it would take away their casual feel.

Players consider sociability to be an important part of social games, though it might not be as essential as in MMO games, for example. Even shallow sociability can enhance the social ties between friends (and strangers), and social motivations can further motivate one to try new games (acquisition), keep interest in a game (retention), and even motivate one to buy gifts for other players with real money (monetization). On the other hand, force-feeding sociability can be an annoyance as well, causing frustration.

\section{REVIEW OF SOCIAL FEATURES}

This section presents the empirical study - the review of social features in 16 social games. First, the method is explained and then the results are presented.

\section{Method}

The empirical study is based on three researchers examining social features by playing social games and analyzing the results with an applied thematic analysis (Guest et al., 2012). The nature of this work is inductive as the list of social features was created based on the findings.

Three researchers played and examined 16 social games on Facebook and recorded their findings individually. The purpose was to identify the social features in the selected games. These social features could be 1) 


\section{ToDiGRA}

game interface elements (Jørgensen, 2013) like a friend's portrait in the game interface, 2) game mechanics (Holopainen, 2011) like sending a virtual item to a friend, 3) game design patterns (Björk \& Holopainen, 2005) like collaborative actions or 4) affordances (Crenshaw \& Nardi, 2016; Pinchbeck, 2009) like an in-game chat window or a clickable game-world avatar. As the researchers focused on the internal level of sociability (Salen \& Zimmerman, 2004), the findings are objective and there is no researcher bias. These features either are or are not programmed into the game. External social features, like Facebook chat for example, would not count as a social feature as it is not an internal part of the game. The games (Table 1) were selected based on their popularity, novelty, or difference to each other to cover a wide spectrum of different kinds of social games from different genres.

\begin{tabular}{|l|l|l|lll|}
\hline Code & Game & Criteria & Launched & Publisher & Genre \\
\hline A & Army Attack & P, N, D & 2011 & Digital Chocolate & Turn-based strategy \\
\hline B & Bubble Witch Saga & P & 2011 & King & Bubble shooter \\
\hline C & Candy Crush Saga & P & 2012 & King & Match-three puzzle \\
\hline D & CastleVille & P & 2011 & Zynga & Builder simulation \\
\hline E & Crazy Penguin Wars & N, D & 2012 & Digital Chocolate & Turn-based PvP combat \\
\hline F & Game of Thrones Ascent & N, D & 2013 & Disruptor Beam & Fantasy RPG \\
\hline G & Gangs of Boomtown & N & 2012 & Digital Chocolate & Western RPG \\
\hline H & Hidden Chronicles & P & 2012 & Zynga & Hidden object \\
\hline I & SongPop & P & 2012 & FreshPlanet & Music trivia \\
\hline J & Yoga Retreat & D & 2012 & Gajatri Studios & Well-being simulation \\
\hline K & War Commander & N, D & 2011 & KIXEYE & Real-time strategy \\
\hline L & Dragon Academy & N & 2013 & Team Chaos & Match-three \\
\hline M & League of Angels & N, D & 2014 & GT Arcade & Fantasy RPG \\
\hline N & Dead Trigger 2 & N, D & 2013 & Madfinger Games & First-person shooter \\
\hline O & Marvel Avengers Alliance & N, D & 2012 & Playdom & Turn-based combat \\
\hline P & Zynga Slots & P & 2012 & Zynga & Casino slots \\
\hline
\end{tabular}

Table 1: The selected social games for the analysis with the selection criteria; popularity $(P)$, novelty $(N)$, and difference $(D)$.

The researchers had experience in expert review methods (e.g. Korhonen \& Koivisto, 2006). They played each game until they were confident about their understanding of the game's social features. This typically took from two days or two weeks up to a month, depending on the game. After the individual examinations were completed, the researchers discussed their findings with each other and combined their individual findings into a master list. Each finding was cross-checked between 
different researchers and different games, and duplicate findings were removed. During this group analysis, the researchers played and examined the games together to validate the findings while utilizing the applied thematic analysis (Guest et al., 2012) method.

Thematic analysis is the most common form of analysis in qualitative research where the data and the findings are examined iteratively by the researchers and categorized into themes and codes. For our purposes, the reviewed social games represent the data that was analyzed and the themes and codes represent the categories of sociability (presence, communication, and interaction) and the identified social features. In games studies, the applied thematic analysis resembles "game playing as method” (Mäyrä, 2008) and the formal analysis of gameplay (Lankoski \& Björk, 2015).

After the analysis and discussion, the features were organized into categories of presence, communication, and interaction. These layers of sociability have been identified in games studies (Consalvo, 2011; Stenros et al., 2011b) and in computer mediated communication, as well (Tu \& McIsaac, 2002). Presence is the core feature of a multiplayer game as the knowledge of others affords further socializing with them. Communication is inherently based on presence and provides the necessary tools for communicating back and forth with either fixed messages or more versatile means. Interaction entails presence and communication, and adds direct player-to-player gameplay (inter)actions.

\section{The Results}

The researchers identified 30 different social features in three categories (presence 11 features, communication 9 features, interaction 10 features). These social features are summarized in Table 2 with their respective codes, categories, titles, and descriptions. 


\section{ToDiGRA}

\begin{tabular}{|c|c|c|}
\hline Code & Social feature & Description \\
\hline PRE1 & Activity information & The game informs the player about friends' actions in the game world. \\
\hline PRE2 & Community challenge & $\begin{array}{l}\text { Community tournaments and other organized events in the game, which are } \\
\text { accessible for the player. }\end{array}$ \\
\hline PRE3 & Automatic friend bonus & Automatic gameplay bonus based on the number of friends playing the game. \\
\hline PRE4 & Friend requirements & $\begin{array}{l}\text { The player cannot complete a gameplay task without requesting her friend to do an } \\
\text { action. }\end{array}$ \\
\hline PRE5 & Off-game sociability & $\begin{array}{l}\text { In-game links to off-game social spaces such as discussion forums, wikis and } \\
\text { Facebook fan pages. }\end{array}$ \\
\hline PRE6 & Presence information & Player receives information about the presence of other players in the game. \\
\hline PRE7 & Scorekeeping & $\begin{array}{l}\text { Ranking and scorekeeping information, where the player can compare her status } \\
\text { against others. }\end{array}$ \\
\hline PRE8 & $\begin{array}{l}\text { Social user-interface } \\
\text { element }\end{array}$ & $\begin{array}{l}\text { Graphical user-interface elements, which have a social reference, such as player } \\
\text { portraits, links, pop-up dialogs etc. }\end{array}$ \\
\hline PRE9 & Visit game space & The player can visit a friend's game space. \\
\hline PRE10 & $\begin{array}{l}\text { Community progress } \\
\text { indicator }\end{array}$ & An indicator representing community progress on a gameplay task. \\
\hline PRE11 & Relocate game space & $\begin{array}{l}\text { Relocation of the player's own game space in the game world, to play in closer } \\
\text { proximity with friends. }\end{array}$ \\
\hline COM1 & $\begin{array}{l}\text { Asynchronous } \\
\text { communication }\end{array}$ & $\begin{array}{l}\text { An ability to communicate with others via asynchronous means (e.g. in-game } \\
\text { message system, discussion board, or sign posts in game space). }\end{array}$ \\
\hline COM2 & $\begin{array}{l}\text { Facebook wall post to a } \\
\text { friend }\end{array}$ & Sending a wall post to a friend's Facebook wall from the game. \\
\hline $\mathrm{COM} 3$ & $\begin{array}{l}\text { Facebook wall post to } \\
\text { own wall and the news } \\
\text { feed }\end{array}$ & $\begin{array}{l}\text { Posting a message from the game on a player's own Facebook wall and the news } \\
\text { feed. }\end{array}$ \\
\hline COM4 & Facebook notification & In-game activity that is presented as a Facebook notification for other players. \\
\hline COM5 & Invite request & $\begin{array}{l}\text { Sending a request to a friend to join the game (also asking a friend to become a } \\
\text { neighbor in some games). }\end{array}$ \\
\hline COM6 & Rematch/Replay & Requesting a rematch or replay from another player. \\
\hline COM7 & Request activity & Requesting an in-game gameplay action from a friend. \\
\hline COM8 & Request items & Requesting an item from a friend. Commonly known as a gift request. \\
\hline COM9 & $\begin{array}{l}\text { Synchronous } \\
\text { communication }\end{array}$ & An ability to communicate with others via synchronous means (e.g. chat). \\
\hline INT1 & Competitive action & Player vs. player gameplay action. \\
\hline INT2 & $\begin{array}{l}\text { Facebook click post } \\
\text { reward }\end{array}$ & Clicking a Facebook game post leads to an in-game reward. \\
\hline INT3 & Interaction reward & Interacting in a friend's game space leads to an in-game reward. \\
\hline INT4 & Receive items & Receiving items sent by friends. Commonly known as accepting gifts. \\
\hline INT5 & Remove friend & Removing a friend from in-game contacts/neighbors. \\
\hline INT6 & Send finite items & Sending an item to a friend. The sending player loses that item from her inventory. \\
\hline INT7 & $\begin{array}{l}\text { Send in-app purchase } \\
\text { items }\end{array}$ & $\begin{array}{l}\text { Buying an item with premium currency in the game and sending the item to a } \\
\text { friend. }\end{array}$ \\
\hline INT8 & Send infinite items & $\begin{array}{l}\text { Sending an infinite item to a friend. Infinite items are free for the player and can } \\
\text { be sent on a daily basis. }\end{array}$ \\
\hline INT9 & Synchronous interaction & Interacting simultaneously with a friend in the same game space. \\
\hline INT10 & Team formation & Forming a team or an alliance through in-game actions. \\
\hline
\end{tabular}

Table 2. The social features identified in the analysis.

Cross-checking each social feature in all of the analyzed games produced a matrix (Table 3), which shows how common each feature is and what the total number of features per game is. The social features were organized into four tier groups based on their frequency. 
A Review of Social Features in Social Network Games 127

\begin{tabular}{|c|c|c|c|c|c|c|c|c|c|c|c|c|c|c|c|c|c|c|c|}
\hline Code & Social feature & $\mathbf{A}$ & B & C & D & $\mathbf{E}$ & $\mathbf{F}$ & G & H & I & $\mathbf{J}$ & $\mathbf{K}$ & $\mathbf{L}$ & $\mathbf{M}$ & $\mathbf{N}$ & o & $\mathbf{P}$ & Total & Tier \\
\hline PRE5 & Off-game sociability & $\mathrm{x}$ & $\mathbf{x}$ & $\mathbf{x}$ & $\mathbf{x}$ & $\mathbf{x}$ & $\mathbf{x}$ & $\mathbf{x}$ & $\mathbf{x}$ & $\mathbf{x}$ & $\mathbf{x}$ & $\mathbf{x}$ & $\mathbf{x}$ & $\mathbf{x}$ & $\mathbf{x}$ & $\mathbf{x}$ & $\mathbf{x}$ & 16 & $1 \mathrm{st}$ \\
\hline PRE6 & Presence information & $\mathbf{x}$ & $\mathbf{x}$ & $\mathbf{x}$ & $\mathbf{x}$ & $\mathbf{x}$ & $\mathbf{x}$ & $\mathbf{x}$ & $\mathbf{x}$ & $\mathbf{x}$ & $\mathbf{x}$ & $\mathbf{x}$ & $\mathbf{x}$ & $\mathbf{x}$ & $\mathbf{x}$ & $\mathbf{x}$ & $\mathbf{x}$ & 16 & 1st \\
\hline PRE7 & Scorekeeping & $x$ & $\mathbf{x}$ & $x$ & $\mathbf{x}$ & $\mathbf{x}$ & $\mathbf{x}$ & $\mathbf{x}$ & $\mathbf{x}$ & $\mathbf{x}$ & $\mathrm{x}$ & $\mathbf{x}$ & $\mathbf{x}$ & $\mathbf{x}$ & $\mathbf{x}$ & $\mathbf{x}$ & $\mathbf{x}$ & 16 & $1 \mathrm{st}$ \\
\hline PRE8 & $\begin{array}{l}\text { Social user-interface } \\
\text { element }\end{array}$ & $\mathbf{x}$ & $\mathbf{x}$ & $x$ & $\mathbf{x}$ & $\mathbf{x}$ & $\mathbf{x}$ & $\mathbf{x}$ & $\mathbf{x}$ & $\mathbf{x}$ & $\mathbf{x}$ & $\mathbf{x}$ & $\mathbf{x}$ & $x$ & $\mathbf{x}$ & $\mathbf{x}$ & $\mathbf{x}$ & 16 & $1 \mathrm{st}$ \\
\hline COM3 & $\begin{array}{l}\text { FB wall post to own } \\
\text { wall and the news feed }\end{array}$ & $\mathbf{x}$ & $\mathbf{x}$ & $\mathbf{x}$ & $\mathbf{x}$ & $\mathbf{x}$ & $\mathbf{x}$ & $\mathbf{x}$ & $\mathbf{x}$ & $\mathbf{x}$ & $\mathbf{x}$ & $\mathbf{x}$ & $\mathbf{x}$ & $\mathbf{x}$ & $\mathbf{x}$ & $\mathbf{x}$ & $\mathbf{x}$ & 16 & 1st \\
\hline $\mathrm{COM} 4$ & Facebook notification & $\mathbf{x}$ & $\mathbf{x}$ & $\mathbf{x}$ & $\mathbf{x}$ & $\mathbf{x}$ & $\mathbf{x}$ & $\mathbf{x}$ & $\mathbf{x}$ & $\mathbf{x}$ & $\mathbf{x}$ & $\mathbf{x}$ & $\mathbf{x}$ & $\mathbf{x}$ & $\mathbf{x}$ & $\mathbf{x}$ & $\mathbf{x}$ & 16 & $1 \mathrm{st}$ \\
\hline COM5 & Invite request & $\mathbf{x}$ & $\mathbf{x}$ & $\mathbf{x}$ & $\mathbf{x}$ & $\mathbf{x}$ & $\mathbf{x}$ & $\mathbf{x}$ & $\mathbf{x}$ & $\mathbf{x}$ & $\mathbf{x}$ & $\mathbf{x}$ & $\mathbf{x}$ & $\mathbf{x}$ & $\mathbf{x}$ & $\mathbf{x}$ & $\mathbf{x}$ & 16 & 1st \\
\hline INT4 & Receive items & $\mathbf{x}$ & $\mathbf{x}$ & $\mathbf{x}$ & $\mathbf{x}$ & $\mathbf{x}$ & $\mathbf{x}$ & $\mathbf{x}$ & $\mathbf{x}$ & & $\mathbf{x}$ & $\mathbf{x}$ & $\mathbf{x}$ & $\mathbf{x}$ & & $\mathbf{x}$ & $\mathbf{x}$ & 14 & 2nd \\
\hline INT9 & Send infinite items & $\mathbf{x}$ & $\mathbf{x}$ & $\mathbf{x}$ & $\mathbf{x}$ & $\mathbf{x}$ & $\mathbf{x}$ & $\mathbf{x}$ & $\mathbf{x}$ & & $\mathbf{x}$ & $\mathbf{x}$ & $\mathbf{x}$ & $\mathbf{x}$ & & $\mathbf{x}$ & $\mathbf{x}$ & 14 & 2nd \\
\hline PRE1 & Activity information & $\mathbf{x}$ & & & $\mathbf{x}$ & $\mathbf{x}$ & $\mathbf{x}$ & $\mathbf{x}$ & $\mathbf{x}$ & $\mathbf{x}$ & $\mathbf{x}$ & $\mathbf{x}$ & $\mathbf{x}$ & & & $\mathbf{x}$ & $\mathbf{x}$ & 12 & 2nd \\
\hline COM8 & Request items & $\mathbf{x}$ & $\mathbf{x}$ & $\mathbf{x}$ & $\mathbf{x}$ & & & $\mathbf{x}$ & $\mathbf{x}$ & & $\mathbf{x}$ & $\mathbf{x}$ & $\mathbf{x}$ & $\mathbf{x}$ & & $\mathbf{x}$ & $\mathbf{x}$ & 12 & 2nd \\
\hline PRE4 & Friend requirements & $\mathbf{x}$ & & $\mathbf{x}$ & $\mathbf{x}$ & $\mathbf{x}$ & $\mathbf{x}$ & $\mathbf{x}$ & $\mathbf{x}$ & $\mathbf{x}$ & $\mathbf{x}$ & & $\mathbf{x}$ & & & $\mathbf{x}$ & & 11 & 2nd \\
\hline PRE2 & Community challenge & $\mathbf{x}$ & & & & $\mathbf{x}$ & $\mathbf{x}$ & $\mathbf{x}$ & & $\mathbf{x}$ & & $\mathbf{x}$ & & $\mathbf{x}$ & $\mathbf{x}$ & $\mathbf{x}$ & $\mathbf{x}$ & 10 & 2nd \\
\hline PRE9 & Visit game space & $\mathbf{x}$ & & & $\mathbf{x}$ & & $\mathbf{x}$ & $\mathbf{x}$ & $\mathbf{x}$ & & $\mathbf{x}$ & $\mathbf{x}$ & & $x$ & & $\mathbf{x}$ & & 9 & 3rd \\
\hline $\mathrm{COM} 2$ & $\begin{array}{l}\text { Facebook wall post to a } \\
\text { friend }\end{array}$ & $\mathbf{x}$ & $\mathbf{x}$ & $x$ & & $\mathbf{x}$ & & $\mathbf{x}$ & $\mathbf{x}$ & $\mathbf{x}$ & $\mathbf{x}$ & & $\mathbf{x}$ & & & & & 9 & 3rd \\
\hline INT1 & Competitive action & $\mathbf{x}$ & & & & $\mathbf{x}$ & $\mathbf{x}$ & $\mathbf{x}$ & $x$ & $\mathbf{x}$ & & $\mathrm{x}$ & & $\mathbf{x}$ & & $\mathbf{x}$ & & 9 & 3rd \\
\hline COM7 & Request activity & $x$ & & & & & $\mathbf{x}$ & $\mathbf{x}$ & $x$ & $\mathbf{x}$ & & & & & & $\mathbf{x}$ & $\mathbf{x}$ & 7 & 3rd \\
\hline COM9 & \begin{tabular}{|l}
$\begin{array}{l}\text { Synchronous } \\
\text { communication }\end{array}$ \\
\end{tabular} & & & & & $\mathbf{x}$ & $\mathbf{x}$ & & & & & $\mathbf{x}$ & & $\mathbf{x}$ & $\mathbf{x}$ & & $\mathbf{x}$ & 6 & 3 rd \\
\hline INT2 & $\begin{array}{l}\text { Facebook click post } \\
\text { reward }\end{array}$ & $\mathbf{x}$ & & & $\mathbf{x}$ & & & $\mathbf{x}$ & $\mathbf{x}$ & & & & & & & $\mathbf{x}$ & $\mathbf{x}$ & 6 & 3rd \\
\hline INT3 & Interaction reward & $\mathbf{x}$ & & & $\mathbf{x}$ & & $\mathbf{x}$ & $\mathbf{x}$ & & & $\mathbf{x}$ & & & & & $\mathbf{x}$ & & 6 & 3rd \\
\hline COM1 & \begin{tabular}{|l|}
$\begin{array}{l}\text { Asynchronous } \\
\text { communication }\end{array}$ \\
\end{tabular} & & & & & & $\mathbf{x}$ & & $\mathbf{x}$ & $\mathbf{x}$ & & & & $x$ & $\mathbf{x}$ & & & 5 & 4th \\
\hline INT6 & Remove friend & $x$ & & & $\mathbf{x}$ & $\mathbf{x}$ & & & & & & & & $\mathbf{x}$ & & $\mathbf{x}$ & & 5 & 4 th \\
\hline INT10 & Synchronous interaction & & & & & $\mathbf{x}$ & & & & & & $\mathbf{x}$ & & $\mathbf{x}$ & & $\mathbf{x}$ & & 4 & 4 th \\
\hline PRE3 & Friend bonus & & & & & $\mathbf{x}$ & & & & $\mathbf{x}$ & & & & & & & $\mathbf{x}$ & 3 & 4 th \\
\hline cOM6 & Rematch/Replay & $x$ & & & & $x$ & & $\mathbf{x}$ & & & & & & & & & & 3 & 4th \\
\hline INT8 & $\begin{array}{l}\text { Send in-app purchase } \\
\text { items }\end{array}$ & & $\mathbf{x}$ & $\mathbf{x}$ & & & & & & & & $\mathbf{x}$ & & & & & & 3 & 4th \\
\hline PRE11 & Relocate game space & & & & & & & & & & & $x$ & & $x$ & & & & 2 & 4 th \\
\hline INT7 & Send finite items & $x$ & & & & & & & & & & & $\mathbf{x}$ & & & & & 2 & 4th \\
\hline INT11 & Team formation & & & & & & $\mathbf{x}$ & & & & & & & $x$ & & & & 2 & 4th \\
\hline PRE10 & $\begin{array}{l}\text { Community progress } \\
\text { indicator }\end{array}$ & & & & & & & & & & & & & & $\mathbf{x}$ & & & 1 & 4 th \\
\hline & Totals Per Game & 22 & 12 & 13 & 16 & 19 & 19 & 20 & 18 & 15 & 15 & 18 & 14 & 19 & 11 & 20 & 16 & & \\
\hline
\end{tabular}

Table 3. The matrix of social features and the analyzed social games.

The most common social features were related to informing the player about her friends and their activities, and inviting non-playing friends 
into the game. The games also provided information on the players' status and showed ranking for comparison. The activity information is presented both in the game interface as well as in the Facebook interface, out of the game. The games also had links to other social spaces outside of the game and Facebook. Basic reciprocity mechanics were present in the form of sending, receiving and requesting in-game (infinite) items. The games also featured mechanics where progression required a friend's activity in some form. This activity could have been anything from becoming a neighbor to sending a certain item, depending on the game. These findings further underline that sociability in the analyzed games is most often based on getting information about other players, inviting them into the game, comparing oneself to others, providing basic mechanics for reciprocity and utilizing game mechanics which require friends' activity for progression. The emphasis is on shallow sociability with passive presence, restricted communication and a lack of game play interaction.

Two of the puzzle games (games B and C), a classic "bubble shooter" and a "match-three" game, featured less social features than all the others. These games had almost identical social features with each other, except for the "Friend requirements", which was only found in game C. In these games, the focus of gameplay was more in the puzzle mechanic and single-player experience, hence sociability was mainly restricted to presence information and sending and receiving items (free moves and power-ups). This underlines that in certain social game genres, sociability is not emphasized. As a side note, both of these games featured in-app purchase items for gifting, which was not a common feature in other analyzed games. A similar feature was only identified in game $\mathrm{K}$ where the players could give out premium currency as a gift. In the aforementioned puzzle games, the buyable power-ups were a powerful aid to complete difficult levels, thus being good gifts for friends, and presumably a profitable business for the developers. In general, a majority of the social features are geared toward acquisition or retention purposes (notifications and requests for example), as only one 
social feature ("Send in-app purchase items") related to monetization was found.

Game N, a first-person shooter game, had the least social features implemented. The game has a strong narrative element and the player follows the story and completes missions. All social features are either from the presence or communication categories, indicating that the game focuses on a single-player experience in its gameplay.

Game A had more social features when compared to the others. This strategy game featured both player vs. environment and player vs. player action. There were many social features, making it socially more versatile than the others. For example, there were many different ways to help friends, and although the player vs. player game mode was not truly a conflict between players, as the friend's units were controlled by artificial intelligence (AI), it gave the impression of playing against a friend. The option to brag about the result through a Facebook wall post enriched the social experience and rivalry.

Some game-specific social features were also revealed. These features were only found in a few games (three games or less) and the features can be considered to be heavily dependent on the game genre. Although they were not common, they provide interesting social twists to the gameplay.

For example, games A, E, and G featured the "Rematch/Replay” feature, which is connected to the player vs. player gameplay. When a player lost a match against another player, she could immediately call for a rematch or replay (the actual gameplay term was dependent on the game, e.g. "Vengeance"). In game E, which featured synchronous gameplay, the other player had to accept the call for rematch whereas in game A and $\mathrm{G}$ the call was automatically accepted, as the player vs. player gameplay was either a single action where statistics were compared for the win condition, or the other player's units were controlled by the AI. 


\section{ToDiGRA}

Another example was the "Relocate game space" feature found in games $\mathrm{K}$ and $\mathrm{M}$. In these games, the players are originally positioned on one server, but it can be changed. To support sociability among playing friends, the players could relocate themselves closer to their friends on the same server, so they could play together on the same world map. This feature is strictly limited to certain kinds of games. For example, in games with no shared game space (games A, D, F, G, H, and J) this kind of a feature would be useless as there are no spatial relationships in the form of a world map, for example.

A third example is "Team formation", which was found only in games $\mathrm{F}$ and $\mathrm{M}$ (the neighbor feature i.e. "Invite request” does not count here as "Team formation”). In game F, this feature was interwoven into the game narrative (which was based on a multi-format franchise) and the feature's absence would have been a serious deficit in the game's fantasy lore. In this game, players could also strengthen alliances with certain ingame actions. In game $\mathrm{M}$, the players were able to create guilds or join existing ones, similar to traditional MMO games (see Siitonen, 2007).

The "Community progress indicator" feature was present only in game $\mathrm{N}$. In this game, the players have a common goal to kill a certain number of zombies. Even though there is no interaction between the players, they can contribute to the objective and monitor when the goal is met in real time. This is an example of a specific kind of a presence feature, which relates to and could be useful in certain kinds of players vs. the environment games.

\section{DISCUSSION}

These results support the earlier views of social games being massively single-player games, as they mostly seem to feature the presence and communication aspects, but not much player-to-player interaction. When compared to MMO games, social games lack in real-time communication, interaction, and team forming, thus making them less 
social in this sense. The social presence with restricted player-to-player interaction resembles the "alone together" phenomenon in MMO games (Ducheneaut, 2006).

However, there is a caveat here. We believe that labelling social games in general as either social or asocial is problematic for two reasons. First, there are many kinds of social games available and some genres emphasize sociability more than others. Second, even the simple games with less social features might be socially engaging due to a game mechanic that affords strong social engagement. Although there are a number of mutually common social features in the examined games, there are game-specific features which may have a great impact on the sociability of the game. The most common features (1st tier) were present in all the analyzed games, and thus these social features can be considered to be tried and true - the core of sociability in social games.

When considering the common social features of social games, the player-to-player interaction, as described by Friedl (2003) and Korhonen \& Koivisto (2007), is usually missing. Looking at Fullerton's (2008) player interaction patterns, social games seem to focus on one or two patterns within a game. Mostly the gameplay follows the multiple individual players vs. the game pattern, sometimes enriched by simple player vs. player patterns. Hence these games have been described as massively parallel single-player games (Järvinen, 2011), which seems to be a fitting term. Only two games featured team competition and a third afforded a multilateral gameplay pattern.

Consalvo (2011) identified a friend bar, gifting, visits, competition/ challenge, and communication as the most common mechanics for social games. We present a more detailed list of social features including a friend bar (in the form of a "Social user-interface element") and communication (in the form of a "Facebook wall post to the news feed or one’s own wall”, “Facebook notification”, and "Invite request”). These are the most common social features along with "Presence information", "Scorekeeping”, and "Off-game sociability". Gifting (in the form of 
"Sending infinite items”, "Receiving items”, and "Requesting items”) was present in the 2nd tier, thus being considered common, but still not found in every analyzed game. Visits and competition/challenge were not identified as common, as they were 3rd tier features, thus being more genre dependent. Compared to Consalvo's study, we provide a deeper analysis with newer games and the accuracy and the validity of the study is improved by utilizing several researchers while providing more detailed results in the form of a concrete list of identified social features.

Interestingly, the social features that are the most common in social games can also be the most hated. Spammy messages, requests, and notifications were considered to be major frustrations by social game players (Paavilainen et al., 2013). This was also found in a playability evaluation study (Paavilainen et al., 2015) where "spammy messages" was one of the domain-specific playability problems in social games. The "Friend requirements" feature, which was found in many games in this study, was also considered to lead to a poor experience in both of the aforementioned studies.

It might be that the game industry's discussion on social games' lack of sociability is narrow and biased towards the so called " Ville games" genre (Lewis et al., 2012), which feature world building and simple social features such as sending and receiving gifts and visiting a friend's game space for score and bonuses. Such games have gained huge popularity in the past, so the discussion has also mostly revolved around them while ignoring other social game genres, which have evolved to offer deeper social experiences.

O’Connor et al. (2015) have studied MMO gamers and their social relationships. They concluded that the sense of community, social identity and social support are clearly visible among the players. In our study, we have identified several social features which probably result in similar experiences. For example, the "Visit game space" and "Activity information" features create a common ground for players and connect them in the game. Social identity can be presented by using the 
"Facebook wall post to a friend" and "Scorekeeping" features. Social support is strongly present in social game features. "Request items" and "Send infinite items" are obvious choices, but there are also other features such as "Synchronous interaction" which enables interaction between the players. In the future, it would be interesting to study whether these social features contribute to the social relationship of the players, as suggested by O’Connor et al. (2015).

The design of social games is often related to the acquisition, retention, and monetization (Fields \& Cotton, 2012) aspects due to their free-toplay revenue model (Paavilainen et al., 2013). Looking at the social features, only one feature ("Send in-app purchase items”) was directly related to monetization while the others were related to acquisition or retention purposes, or both, as there are social features where the distinction might be difficult to call.

To enhance the sociability in social games, designers should implement social features similar to MMO games, focusing on communication and interaction as well as team forming. Genre-specific aspects should be taken into consideration, as social engagement can be achieved with a "less is more" attitude without falling into a feature creep. Another approach is to offer a wide range of game-specific social features, which offer a selection of social affordances in a given situation. The 1st and 2nd (and even 3rd) tier social features offer the baseline to start with, while the genre provides the context for developing specific social features to enrich the social experience. There are already social games with versatile social features. Earlier it might have been easier to make clear distinctions between social games and MMO games, but as social games are evolving further, they are closing the gap and blurring the line between the two.

The contributions of this study are three-fold. First, we have provided detailed understanding on the sociability and the social features in social games through examining the discussion around them and analyzing their social features. The list of social features can be used to aid the 


\section{ToDiGRA}

analysis of social games and it can be further expanded with new findings. Second, the identified social features can be used as heuristics to evaluate the sociability of social games - or any game with social network integration. Third, as this study shows the actual social features used in the design of social games, it also reveals what areas or features are neglected, thus acting as a source for innovation. Designing social features related to interaction and monetization could be beneficial for the developers. An earlier study shows that social gameplay is important for engagement and monetization for both desktop and mobile casual (social) games (Alsén et al, 2016). As Christou et al. (2013b) have called for methods and guidelines for designing and evaluating the sociability in online games, we believe our study is contributing to this call from the perspective of social games.

There are limitations in this study. First, the sample size of 16 games does not allow us to make bold generalizations across the domain. Second, there is the possibility that the researchers missed some features, although being thorough and experienced in analyzing games. Third, as social games are constantly updated, it might be that some features were added, removed, and changed during or after the study. In the future, it would be interesting to study which social features are important for the players. For such a study, the provided list of social features would be useful for survey or interview purposes.

\section{CONCLUSION}

This paper has discussed the sociability and social features of Facebook social games. Questioned by the game industry and sometimes even hated by the players, sociability has an interesting role in social games. By examining 16 social games we identified 30 social features which were organized into three categories: presence, communication, and interaction. The most common features were related to presence and communication, while actual player-to-player interaction was lacking. A majority of the features were focused on player acquisition or retention, 
neglecting monetization. Social games cannot be deemed as social or asocial, as this is up to the individual game. Social games share a common set of social features, but there are many game-specific social features which can enhance the sociability of a game. These findings can be used by both academics and industry practitioners for the benefit of the study and design of social games - or other video games with social network integration.

\section{BIBLIOGRAPHY}

Alsén, A., Runge, J., Drachen, A., \& Klapper, D. (2016). Play with me? Understanding and measuring the social aspect of casual gaming. Presentation in the First Workshop on Player Analytics in 12th AAAI Conference on Artificial Intelligence and Interactive Digital Entertainment, 9th October 2016, San Fransisco, CA. USA.

Arrington, M. (2009). Scamville: The social gaming ecosystem of hell. Retrieved from http://techcrunch.com/2009/10/31/scamville-the-socialgaming-ecosystem-of-hell/

Björk, S. \& Holopainen, J. (2005). Patterns in Game Design. Newton Center, MA: Charles River Media.

Bogost, I. (2004). Asynchronous Multiplay: Futures for Casual Multiplayer Experience. Other Players Conference on Multiplayer Phenomena, December 2004.

Bogost, I. (2010). Cow Clicker. The making of obsession [Blog post]. Retrieved from http://www.bogost.com/blog/cow_clicker_1.shtml

Brightman, J. (2012). Zynga: Social games are still not truly social. Retrieved from http://www.gamesindustry.biz/articles/ 2012-04-11-zynga-social-games-are-still-not-truly-social 
Caldwell, B. (2011). Jonathan Blow interview: Do you believe social games are evil? "Yes. Absolutely." Retrieved from http://www.pcgamer.com/previews/jonathan-blow-interview-socialgame-designers-goal-is-to-degrade-the-players-quality-of-life/

Chen, M. (2009). Crop-stealing on Happy Farm: An addiction to affiliation. Retrieved from http://www.china.org.cn/china/2009-12/10/ content_19044478.htm

Crenshaw, N., \& Nardi. B. (2016). It was more than just a game, it was community: Social affordances in online games. In Proceedings of the 49th Hawaii International Conference on Systems Sciences. Retrieved from https://www.computer.org/csdl/proceedings/hicss/2016/5670/00/ 5670d781.pdf

Christou, G., Law, E., Geerts, D., Nacke, L., \& Zaphiris, P. (2013a). Designing and evaluating sociability in online video games. In CHI'13 Extended Abstracts on Human Factors in Computing Systems.

Christou, G., Law, E., Zaphiris, P., \& Ang, C. (2013b). Challenges of designing for sociability on enhance player experience in massively multi-player online role-playing games. Behaviour \& Information Technology, 32(7), 724-734.

Consalvo, M. (2011). Using your friends: Social mechanics in social games. In Proceedings of Foundations of Digital Games, ACM Press 2011, 188-195.

Costikyan, G. (2011). Unsocial 'Social' Games. Retrieved from http://www.gamasutra.com/view/feature/134755/

unsocial_social_games.php

de Kort, Y.A.W. \& Ijsselsteijn, W.A. (2008). People, Places, and Play: Player Experience in a Socio-Spatial Context. ACM Computers in Entertainment 6(2). 
Dredge, S. (2013). Ex-Zynga studio boss Matthew Wiggins on where social games went wrong. Retrieved from http://www.theguardian.com/ technology/appsblog/2013/jul/18/jiggerypokery-social-gamesfreemium-zynga

Ducheneaut, N., Yee, N., Nickell, E., \& Moore, R.J. (2006). 'Alone together?' exploring the social dynamics of massively multiplayer online games. ACM Conference on Human Factors in Computing Systems (CHI 2006), ACM Press 2006, 407-416.

EA (2012). SimCity Social breaks ground on Facebook [Press release]. Retrieved from http://investor.ea.com/ releasedetail.cfm?ReleaseID $=679835$

Farzan, R., Dabbish, L., Kraut, R., \& Postmes, T. (2010). Increasing commitment to online communities by desiging for social presence. In Proceedings of Computer Supported Cooperative Work, CSCW, ACM Press 2010, 321-330.

Fields, T. \& Cotton, B. (2012). Social game design. Monetization methods and mechanics. Waltham, MA: Morgan Kaufmann.

Fullerton, T. (2008). Game design workshop: A playcentric approach to creating innovative games (2nd Edition). Burlington, MA: Morgan Kaufmann.

Friedl, M. (2003). Online game interactivity theory. Hingham, MA: Charles River Media.

Grayson, N. (2012). Are social games really social? Games? Retrieved from https://www.rockpapershotgun.com/2012/05/22/are-social-gamesreally-social-games/

Guest, G., MacQueen, K.M., \& Namey, E.E. (2012). Applied Thematic Analysis. Thousand Oaks, CA: SAGE. 
Holopainen, J. (2011). Foundations of Gameplay (Doctoral dissertation). Blekinge Institute of Technology.

Hou, J. (2011). Uses and gratifications of social games: Blending social networking and game play. First Monday 16, 7. Retrieved from: http://firstmonday.org/article/view/3517/3020

Isbister, K. (2010). Enabling social play: A framework for design and evaluation. Chapter 2 in Bernhaupt R. (Ed.) Evaluating user experience in games: Concepts and Methods. London, UK: Springer, 11-22.

Järvinen, A. (2009). Game design for social networks: Interaction design for playful disposition. In Proceedings of Sandbox'09, ACM Press (2009), 95-102.

Järvinen, A. (2010). The state of social in social games. Retrieved from http://www.gamasutra.com/view/feature/134548/

the_state_of_social_in_social_games.php

Järvinen, A. (2011). State of social in social games [Presentation]. Retrieved from http://casualconnect.org/lectures/community-social/ state-of-social-in-social-games/

Jørgensen, K. (2013). Gameworld Interfaces. Cambridge, MA: MIT Press.

Kallio, K.P., Mäyrä, F., \& Kaipainen, K. (2011). At least nine ways to play: approaching gamer mentalities. Games \& Culture 6, 4, 327-353.

Kim, J., Chang, Y., \& Myeong-Cheol, P. (2013). Why do people like to play social network games with their friends? A focus on sociability and playability. In Proceedings of PACIS 2013. Retrieved from http://aisel.aisnet.org/pacis2013/78/

Korhonen, H. \& Koivisto, E.M.I. (2006). Playability Heuristics for Mobile Games. In MobileHCI, ACM Press, 9-16. 
Korhonen, H. \& Koivisto, E. M. I. (2007). Playability heuristics for mobile multi-player games. In Proceedings of the International Conference on Digital Interactive Media in Entertainment and Arts, DIMEA ACM Press, 28-35.

Koster, R. (2011). Social mechanics for social games. GDC 2011 [Presentation]. Retrieved from http://www.gdcvault.com/play/1014555/ Social-Mechanics-for-Social-Games

Lankoski, P. \& Björk, S. (2015). Formal Analysis of Gameplay. In P. Lankoski \& S. Björk (Eds.) Game Research Methods: An Overview. ETC Press. Retrieved from http://press.etc.cmu.edu/content/gameresearch-methods-overview

Lewis, C., Wardrip-Fruin, N., \& Whitehead, J. (2012). Motivational game design patterns of 'Ville games. In Proceedings of Foundations of Digital Games (FDG 2012), Raleigh, NC.

Losh, E. (2008). In polite company: Rules of play in five Facebook games. In Proceedings of Advances in Computer Entertainment and Technology, ACE’08, ACM Press, 345-351.

Luton, W. (2013). Free-to-play: Making money from games you give away. New Riders.

McEwan G., Gutwin C., Mandryk R., \& Nacke L. (2012). “I’m just here to play games:” Social dynamics and sociability in an online game site. In Proceedings of Computer Supported Cooperative Work, CSCW, ACM Press 2012, 549-558.

Mäyrä, F. (2008). An introduction to game studies: Games in culture. London, UK: Sage.

Nutt, C. (2012). Facebook: Social game devs must make their games actually social. Retrieved from http:/gamasutra.com/view/news/ 180310/ 
Facebook_Social_game_devs_must_make_their_games_actually_social .php

O’Connor E.L., Longman H., White K.M., \& Obst P.L. (2015). Sense of Community, Social Identity and Social Support among Players of Massively Multiplayer Online Games (MMOGs): A Qualitative Analysis, Journal of Community \& Applied Social Psychology, 25, 6, 459.473 .

Paavilainen, J., Alha, K., \& Korhonen, H. (2015). Domain-specific playability problems in social network games. Int. Journal of Arts and Technology, 8, 4, Inderscience.

Paavilainen, J., Hamari, J., Stenros., J., \& Kinnunen, J. (2013). Social Network Games: Players’ Perspectives. Simulation \& Gaming 44, 6, 794-820.

Pinchbeck, D. (2009). An affordance based model for gameplay. In Proceedings of DiGRA 2009.

Price, M.L. \& Wearn, N. (2012). Viral or social friends? "I want to build relationships while playing a game. I want to meet real people.” Retrieved from http://eprints.staffs.ac.uk/1366/

Radd, D. (2012). Idle Games says you can't have a social game without real-time play. Retrieved from http://www.gamesindustry.biz/articles/ 2012-04-07-idle-minds-says-you-cant-have-a-social-game-without-realtime-play

Radoff, J. (2011). Social games are evil (and other stupid memes) [Blog post]. Retrieved from http://radoff.com/blog/2011/03/03/social-gamesevil-stupid-memes/

Rose, M. (2011). Braid's Blow: Social games are 'not very social'. Retrieved from http://www.gamasutra.com/view/news/123490/ Braids_Blow_Social_Games_Are_Not_Very_Social.php\#.UOhy6nfIVo M 
Salen, K. \& Zimmerman, E. (2004). Rules of play. Game design fundamentals. Cambridge, MA: MIT Press.

Shin, D.-H. \& Shin Y.-J. (2011). Why do people play social network games. Computers in Human Behavior 27, 2, 852-861.

Siitonen, M. (2007). Social Interaction in Online Multiplayer Communities (Doctoral dissertation). University of Jyväskylä.

Stenros, J., Paavilainen, J., \& Kinnunen, J. (2011a). Giving Good 'Face': Playful Performances of Self in Facebook. In Proceedings of Academic MindTrek (2011), ACM Press, 153-160.

Stenros, J., Paavilainen, J., \& Mäyrä, F. (2011b). Social interaction in games. International Journal of Arts and Technology 4, 3, 342-358.

Tu, C.-H. \& McIsaac, M. (2002). The Relationship of Social Presence and Interaction in Online Classes. The American Journal of Distance Education 16, 3, 131-150.

Tyni, H., Sotamaa, O., \& Toivonen, S. (2011). Howdy pardner!: on freeto-play, sociability and rhythm design in FrontierVille. In Proceedings of Academic MindTrek, (2011), ACM Press, 22-29.

Ventrice, T. (2009). Building the foundation of a social future. Retrieved from http://www.gamasutra.com/view/feature/4210/ building_the_foundation_of_a_.php

Wohn, D.Y., Lampe, C., Wash, R., Ellison, N., \& Vitak, J. (2011). “The "S" in Social Network Games: Initiating, Maintaining, and Enhancing Relationships,” System Sciences (HICSS), 2011 44th Hawaii International Conference

Wohn, D.Y., \& Lee, Y-H. (2013). Players of Facebook games and how they play. Entertainment Computing, 4, 171-178 
142 ToDiGRA

Yee, N. (2006). Motivations for Play in Online Games. CyberPsychology \& Behavior 9, 6, 772- 775 .

Zagal, J., Björk, S., \& Lewis, C. (2013). Dark patterns in the design of games. In Proceedings of the Foundation of Digital Games 2013 (pp. 39-46). Retrieved from: http://www.fdg2013.org/program/papers/ paper06_zagal_etal.pdf 